\title{
CHIMPANZEES IN WESTERN UGANDA
}

\section{By Ken Stott, Jun., and C. Jackson Selsor}

The following observations on the Long-haired or Schweinfurth's Chimpanzee, Pan troglodytes schweinfurthii, represent several brief but concerted efforts to locate wild chimpanzees in western Uganda in the months of October and November, 1957 and 1958. The authors' appreciation is extended to Mrs. Belle J. Benchley and to Dr. Ernst Schwarz for reading the manuscript and providing helpful suggestions.

Schweinfurth's Chimpanzee occupies, or has occupied in the recent past, most forested areas in Uganda from the Belgian Congo border east to "Lake Albert and Lake Victoria" (Schwarz, 1944) as well as the Budongo Forest (Hollister, 1924) and the Bugoma Forest (Pitman, 1954), both of these forests lying east of Lake Albert. The north-south distribution of the race in Uganda extends from the Bunyoro District south to the Kigezi District in the south-western corner of the country (Glover M. Allen, in Harper 1945).

Chimpanzees had previously been reported as occurring in each of the following areas :-

(1) The Gorilla Sanctuary on the Uganda slopes of Mugahinga and Muhavura, Birunga volcanoes, Kigezi District.

(2) The Kayonsa or Impenetrable Forest, Kigezi District.

(3) The Maramagambo Forest, Ankole District.

(4) The Kibale Forest, Toro District.

The first two involve terrain that is generally precipitous with little even semi-level ground. The vegetation consists of nearly continuous forest. In the Birunga region, extensive stands of bamboo are interspersed with expanses of broad-leaf vegetation : medium height trees (mainly hagenias) with an undergrowth of giant lobelias, wild "celery", wild "parsley" and stinging nettles. The Kayonsa Forest includes also higher trees, some species having heavily buttressed trunks; bamboo is less abundant. Palms were not noted in either area.

The Maramagambo Forest consists for the most part of gently rolling foothills on an alluvial slope south-east of Lake Edward. There the forests are drier, most of the trees are of small or medium height; heavily buttressed trees are few. Bamboo was not noted but Phoenix reclinata palms were a conspicuous botanical element in the vicinity of several small lakes. The Maramagambo involves a broad and continuous central expanse 
of woodland, with narrow forest extensions that follow the valley-bottoms up into the hills on the south and east, and border rivers that flow towards Lake Edward on the north-west. These peripheral extensions are separated from one another distally by grassland or bush.

The more humid Kibale Forest consists chiefly of a network of valley-bottom or crater-bottom woods, with treeless intervening hilltops. Broad uninterrupted expanses of forest are few. Valley forests are often no more than 200 or 300 feet wide and are usually connected to one another by means of wooded gaps between hills. Trees are generally higher than in the Maramagambo, and species that develop heavily buttressed trunks are well represented. The canopy in Kibale is generally the densest observed in the four areas visited.

The first three areas boast sparse human habitation and limited cultivation. The Kibale area, however, is well populated and the hilltops that separate the bands of forest are extensively cultivated, supporting commercial plantings of tea, coffee and sugar cane that grow to the forest edge.

Although reports persist that chimpanzees occur in the Gorilla Sanctuary on the Uganda slopes of Muhavura and Mugahinga, Mr. M. W. Baumgartel, of Kisoro, assured us that during more than three years in which he has studied mountain gorillas in the volcano forests, neither he nor his native trackers have seen or heard any evidence of chimpanzees. In a letter dated 21st March, 1959, to the authors, Mr. Baumgartel states: "I can safely say that chimpanzees do not occur in our gorilla sanctuary." Though the authors succeeded in observing gorillas on the volcano slopes, they neither saw nor heard chimpanzees, nor did they encounter their nests.

In the Kayonsa Forest, chimpanzees were neither seen nor heard. However, two rather old nests, about 30 feet from the ground in the same tree, were noticed. They were located at perhaps 6,000 feet in a valley on the Luhiza road, approximately 50 miles north of Kisoro by road.

In the Maramagambo, a somewhat atypical chimpanzee habitat due to the dry, generally scrubby nature of the vegetation, neither chimpanzees nor nests were observed. In November, 1957, Mr. Stephan Siranyo, in charge of an experimental fisheries camp in the Maramagambo, showed the authors a log upon which he had recently surprised two chimpanzees on the shore of Lake Nyamisigeri. In November, 1958, Captain Frank Poppleton, warden of Queen Elizabeth Park, told the authors how, a few days earlier, he had seen a young chimpanzee in a 
gallery forest where the Ntungwe River crosses the new Congo road in the southern end of the park. Other reports, including one from Mr. Baumgartel, indicate that chimpanzees are not infrequently observed from the new Congo road in this section of the Maramagambo.

In the Kibale Forest, near Fort Portal, chimpanzees were both heard and seen, and a number of nests noted. The chimpanzee population of the Kibale Forest Reserve has not, to our knowledge, been accurately tabulated. That it is considerable, and probably greater than in any of the other areas visited, was indicated by the frequency with which chimpanzees are heard or encountered by local residents and by the abundance of tree nests throughout forested sectors.

Despite the fact that chimpanzees unquestionably occur in three of the four areas visited, they are not easily found. Chimpanzees wander freely within the extensive confines of suitable habitat, without any apparent reason except the presence or absence of food, predators or other chimpanzee troops. Their meanderings do not seem to involve well-defined routes or periodicity. Standing and running water was abundant in all areas. Human residents of the Maramagambo and Kibale forests stated that months sometimes passed without any audible indication of the presence of chimpanzees. The vocalizations which accompany chimpanzee activities might then be heard for a period of several days before the troop moved on to another area.

We ourselves heard chimpanzee calls at three different points in the Kibale Forest-on 29th October, 1958, at 5.30 p.m., on 30th October at 10.15 a.m. and from 11 a.m. until noon. The two morning instances involved several voices, the late afternoon instance a single voice only. In each case we tried to find the chimpanzee responsible, but only on the morning of 30th October were we successful.

We had been driven by Mr. D. B. G. Hyland in a Land Rover to a point about 5 miles south-east of Fort Portal, on a trail that skirted the crest of a small forested crater. On the way we had stopped frequently, in the hope of hearing a chimpanzee call. Then at last we heard the unmistakable hooting call coming from about a quarter of a mile away, in the depth of the crater forest. With a Game Department African guard and a locally born native tracker, we left the Land Rover and plunged down the crater slope. The chimpanzee calls ceased abruptly. Four or five minutes later a single chimpanzee began calling and was almost immediately joined by several other 
voices. The chorus continued for about a minute, then all voices became silent at almost the same instant. Again we moved as quietly as possible in the direction from which we thought the calls had come. After another interval of four or five minutes, the chorus began again, instigated once more by the calling of a single member of the troop.

Throughout much of the following hour during which we trailed and eventually saw the chimpanzees, the chorus came at intervals, beginning always with the voice of one individual, to be joined almost immediately by other members of the group; then all voices in the chorus would stop almost simultaneously. Each time the chorus began the voices would come from new positions, showing that during the periods of silence the chimpanzees were on the move. On several occasions the calls came sometimes from treetops and sometimes from ground level, on all sides of us ; some voices seeming nearer, others more distant. We judged that the chimpanzee troop was sometimes spread out over an area of perhaps as much as 100 yards square.

Chimpanzee choruses have been interpreted as a means of frightening away potential enemies. There is little doubt that such bedlamic cacophony can and does upon occasion do so, but we suggest that it also serves to aquaint members of a troop on the move with the position and progress of other members, particularly where dense vegetation limits visibility to a few yards or even feet.

Observations of chimpanzees in French Guinea (Nissen, 1931) indicated that "Almost without exception, sound-production ceases promptly when the proximity of human beings becomes known to the animals ; it is not often resumed for an hour or more thereafter". This was not so with the Kibale chimpanzees. They were almost certainly aware of our presence, progress and position at all times, yet their vocalizations came at frequent intervals and throughout the period we followed the troop through the forest.

On several occasions the screaming sessions were accompanied by brief but resounding drumming by a single individual on either a $\log$ or a tree buttress. The drumming consisted of from six to ten thuds in rapid succession. In one instance it was preceded and followed by the sound of feet slapping against hard-packed mud at the base of a tree. We subsequently examined the spot, found the resulting footprints and simulated the drumming sounds by slapping the side of a tree buttress with our bare, open and slightly cupped hands. 
With the help of the game guard and the tracker, both of whom had experienced almost daily contact with wild chimpanzees, we estimated that there were at least six members in the troop, and more probably seven or eight. This was based on the location of individuals seen, the number of voices distinguished and the directions from which these voices came. Between the five of us we saw five chimpanzees : a large adult running on the ground was clearly seen by the guard and tracker in the lead (who declared, probably correctly, that it was a male) but only as a fleeting shadow by those of us in the rear ; for at least 15 minutes our whole party watched an adult female and two half-grown chimpanzees feeding in a tree ; Mr. Hyland saw briefly a single adult animal as it ran across the ground.

The chimpanzees we saw on the ground were silent. Calls for the most part came from overhead; when a call did seem to come from ground level it was usually accompanied by drumming, suggesting that the drummer was also the groundlevel screamer. The trio of chimpanzees we watched feeding together in a tree neither called nor responded to calls of other chimpanzees. The calls from other troop members during this period were not choral efforts, but involved a single voice only. These solo hootings were somewhat plaintive, lacking both the hysterical nature and the volume that had characterized group efforts when first we had begun to follow the troop.

While the chimpanzees were feeding we stood motionless and silent. But we were convinced that they were aware of our presence, because of occasional glances in our direction. What we had interpreted as initial alarm had apparently subsided, giving way to partial tolerance of our proximity. These three feeding chimpanzees had been spotted by our tracker. Their lusterless blackish coats made them somewhat difficult to see against the shadowy forest background, even though they were no more than 50 feet away. They were squatting close together approximately 25 feet from the ground on a large branch about 6 feet from the trunk of the tree. The adult female was nearest to us, facing us, and in full sunlight. Two half-grown animals were between her and the trunk, partly shaded by overhanging boughs.

We viewed the chimpanzees at eye level from directly across a small ravine. Our view was unobstructed and through binoculars we could clearly see the shaggy nature of the coat and the mutton-chop cheek tufts that characterize schweinfurthii. The brown eyes of the female and the semi-shiny quality 
of her black facial skin were visible in the sunshine. The faces of the smaller chimpanzees were paler and brownish.

The immense tree in which the chimpanzees were feeding bore a profusion of cherry-sized, smooth-skinned, yellow fruits that had attracted not only the chimpanzees but two species of lesser primates as well (see "Association with other primates "). The female chimpanzee would obtain the fruit from a squatting position by means of a forearm with which she would encircle and draw toward her an accessible bough. She would then detach the fruit with her conspicuously prehensile lips. When she had removed most of the fruit from a bough she would release it and draw another one towards her. She never used a hand for this. The younger chimpanzees sometimes took the fruit in the same way, but they were also seen to pluck the yellow fruit with their hands and put it in their mouths with their fingers. Whereas the adult female remained in one spot to feed, the younger chimpanzees moved gradually back along the branch, pausing to feed en route, until eventually they reached the trunk and dropped to a lower branch out of our sight.

After 15 minutes of placid feeding, the female reached out and hooked a hand over a stocky branch nearer the trunk of the tree. Then she swung her body forward and hung momentarily from one hand, apparently watching us. Then with her free hand she grasped a vertical liana near the trunk and pulled herself toward it, propping her feet against the trunk and removing the hand by which she had hung from the branch. Then she moved rapidly down the trunk, hindside first, and disappeared from view.

We slid down the hillside, scrambled across the ravine and up the other side, unavoidably making considerable noise. Once again the hysterical chorus began, some voices coming from the side of the ravine we had just left. In spite of strenuous efforts we failed to see the chimpanzees again. The band moved through the forest more rapidly than before, screaming in unison periodically with intervening intervals of silence, and soon leaving us far behind.

Nocturnal Activity.-Although chimpanzee choruses are to be heard not only by day but also by night, though less commonly, they are generally considered to be nocturnally inactive. However, the fact that they do upon occasion move about at night is suggested by an incident related to us by a European in the Fort Portal area. A few days before our arrival he had been driving at about 10 p.m. along a road that crossed a cane 
field. As he turned a corner his headlights fell upon an adult (male?) chimpanzee walking toward him in the road. The chimpanzee stopped, stood stock still momentarily, then plunged into the cane field at one side of the road and " ran screaming through the field back in the direction of the forest".

Abnormal Colouration.-Dr. Nissen (Nissen, 1931) has described an occasion upon which "I thought I saw an animal with light brown or orange-coloured hair" and further mentions a report of a captive animal at Pastoria, French Guinea, that "had exhibited this same curious and exceptional colouration". The authors observed a similarly coloured living chimpanzee in the Game Department zoo in Entebbe, Uganda, on 3rd November, 1958. It was approximately two years of age and had been brought, in an ailing and hairless condition, by natives to Game Department officials. With medical care and proper nutrition, the young chimpanzee had been restored to better health and a new coat of hair had grown to normal length with abnormal colouration. The hue might best be described as pale brownishorange. It is not known whether or not the chimpanzee had been normally coloured before its illness. A captive-bred specimen born in the San Diego Zoological Gardens ten years ago to normally coloured parents (whose subsequent progeny were also normally coloured) was characterized by the same colouration from infancy onward. It lived for less than two years, during which time it was never a healthy nor normally active infant.

Association with Other Primates.-Haddow (1952) states that neither chimpanzees nor baboons associate closely with other primates when feeding or resting. Our own limited observations would seem to contradict these conclusions. In the Kibale Forest chimpanzees were seen feeding in the same tree and in close proximity to foraging Red-capped Colobus Monkeys, Colobus badius tephrosceles, and Schmidt's Red-tailed Monkeys, Cercopithecus nictitans schmidti; and in the Maramagambo a large troop of Anubis Baboons, Papio a. anubis, was observed in the top of a fruiting wild fig tree that was also occupied by Black-and-white Colobus Monkeys, Colobus polykomos occidentalis. Since both Pan and Papio apparently enter, at least on a limited basis, the feeding association picture, it would seem worthwhile to list the various primates we encountered in chimpanzee forests, at the same time indicating such feeding associations as we were able to record.

In the Kayonsa Forest we observed an adult male Stuhlmann's Blue Monkey, Cercopithecus mitis stuhlmanni, feeding less than 
3 feet away from and in the same tree as two Mountain Redtailed Monkeys, C. nictitans montanus. Higher in the hills but in the same vicinity we noted a troop of eight L'Hoest's Monkeys, C. l'hoesti, on the ground in a small clearing.

In the Maramagambo we noted Anubis Baboons feeding among Black-and-white Colobus and examples of that form of Colobus foraging in the same tree as Uganda Vervets, Cercopithecus aethiops centralis. Schmidt's Red-tailed Monkey is also known to occur in the Maramagambo.

In the Kibale Forest we noted the following species of primates in addition to Schweinfurth's Chimpanzee: Black-and-white Colobus, Red-capped Colobus, Stuhlmann's Blue Monkey, Schmidt's Red-tailed Monkey, and a dark-cheeked form of the Grey-cheeked Mangabey, Cercocebus albigena johnstoni. The following feeding associations were noted: Schmidt's Redtailed Monkeys with Black-and-white Colobus only; Schmidt's Red-tailed Monkeys with both species of Colobus; Schmidt's Red-tailed Monkeys with a Stuhlmann's Blue Monkey; Redcapped Colobus with Black-and-white Colobus only; and Red-capped Colobus with Grey-cheeked Mangabeys.

\section{LITERATURE CITED}

Handow, A. J., 1952. Field and laboratory studies on an African monkey, Cercopithecus ascanius schmidti Matschie. Proc. Zool. Soc. Lond., vol. 122, part iii, 297-394.

Harper, Francis, 1945. Extinct and Vanishing Mammals of the Old World. Amer. Com. Int. Wild Life Prot., spec. pub., 12, 1-850.

Hollister, N., 1924. East African mammals in the United States National Museum. Smith. Insti. Bull., 99, part iii, 1-164.

Nissen, Henry W., 1931. A field study of the chimpanzee, observations of chimpanzee behavior and environment in western French Guinea. Comp. Psych. Mono., vol. 8, no. 1, serial no. 36, 1-122.

Pitman, Charles R. S., 1954. The influence of the Belgian Congo on the distribution of Uganda's primates, and some of their characteristics. Ann. Mus. Congo Tervuren, nov. ser. in $-4^{\circ}$, vol. i, $47-55$.

Schwarz, E., 1934. On the local races of the chimpanzee. Ann. Mag. Nat. Hist., ser. 10 , vol. 13, no. 78, 576-583.

Naturat History Museum,

San Diego,

CaLJfFornia.

28th April, 1959. 